\title{
Experimental Measurement of Electron Heat Diffusivity in a Tokamak
}

\author{
J. D. Callen \\ G. L. Jahns
}




\section{DISCLAIMER}

This report was prepared as an account of work sponsored by an agency of the United States Government. Neither the United States Government nor any agency Thereof, nor any of their employees, makes any warranty, express or implied, or assumes any legal liability or responsibility for the accuracy, completeness, or usefulness of any information, apparatus, product, or process disclosed, or represents that its use would not infringe privately owned rights. Reference herein to any specific commercial product, process, or service by trade name, trademark, manufacturer, or otherwise does not necessarily constitute or imply its endorsement, recommendation, or favoring by the United States Government or any agency thereof. The views and opinions of authors expressed herein do not necessarily state or reflect those of the United States Government or any agency thereof. 


\section{DISCLAIMER}

Portions of this document may be illegible in electronic image products. Images are produced from the best available original document. 
Printed in the United States of America: Available from National Technical Information Service

U.S. Department of Commerce

5285 Port Royal Road, Springfield, Virginia 22161

Price: Printed Copy \$4.00; Microfiche \$2.25

This report was prepared as an account of work sponsored by the United States Government. Neither the United States nor the Energy Research and Development Administration/United States Nuclear Regulatory Commission, nor any of their employees, nor any of their contractors, subcontractors, or their employees, makes any warranty, express or implied, or assumes any legal liability or responsibility for the accuracy, completeness or usefulness of any information, apparatus, product or process disclosed, or represents that its use would not infringe privately owned rights. 
Contract No. W-7405-eng-26

Thermonuclear Division

\section{EXPERIMENTAL MEASUREMENT OF ELECTRON HEAT}

DIFFUSIVITY IN A TOKAMAK

J. D. Callen and G. L. Jahns

Oak Ridge National Laboratory, Oak Ridge, Tennessee

(To be submitted to Physical Review Letters)

JUNE 1976

NOTICE This document contains information of a preliminary nature and was prepared primarlly for internal use at the Ouk Ridge Natlonal Laboratory. It is subject to revision or correction and therefore does not represent a final report.

OAK RIDGE NATIONAL LABORATORY

Oak Ridge, Tennessee 37830

operated by

UNION CARBIDE CORPORATION

for the

ENERGY RESEARCH AND DEVELOPMENT ADMINISTRATION

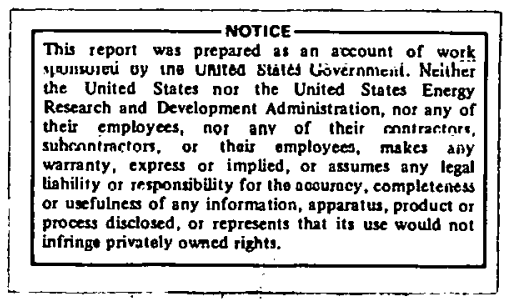




\title{
EXPERIMENTAL MEASUREMENT OF ELECTRON HEAT \\ DIFFUSIVITY IN .A TOKAMAK *
}

J. D. Callen and G. L. Jahns

Oak Ridge National Laboratory, Oak Ridge, Tennessee 37830

\begin{abstract}
The electron temperature perturbation produced by internal disruptions in the center of the Oak Ridge Tokamak (ORMAK) is followed with a multi-chord soft $x$-ray detector array. The space-time evolution is found to be diffusive in character, with a conduction coefficient larger by a factor of 2.5 - 15 than that implied by the energy containment time, apparently because it is a measurement for the small group of electrons whose energies exceed the cut-off energy of the detectors.
\end{abstract}

A useful model for understanding the energy transport governing the behavior of tokanak discharges is a three-region plasma model. The central core region $\left(r<a_{D}\right.$, the disruption radius) suffers internal disruptions ${ }^{1}$ repeatedly as the safety factor $q$ drops below unity. Outside this core region there is typically a large "middle" region (confinement zone) where tearing modes, plasma turbulence and/or unknown processes are responsible for "anomalous" heat transport, which primarily determines the energy containment of the device. Finally, there is a "plasma edge" region $\left(r>a_{0}\right.$ ) dominated by atomic physics effects such as radiation, impurity refluxing, charge-exchange, etc.

\footnotetext{
${ }^{\star}$ Research sponsored by Energy Research and Development Administration under contract with Union Carbide Corporation.
} 
The internal disruptions inside $a_{D}$ manifest themselves as sudden drops in the soft $x$-ray signal level, followed by slower recoveries, giving the characteristic sawtooth pattern evident in Fig. 1. The standard interpretation ${ }^{1}$ of the sudden drop is that the electron temperature is decreasing as heat is rapidly lost from the central region. This process results in a pulse of heat into the volume just outside the disruption radius, and predictably, as seen in Fig. 1, the $x$-ray signals outside $a_{n}$ show a pulse-like increase at the time of the sudden decrease inside. By following the propagation of these perturbations through the critical middle region, we can, directly and for the first time, examine the fundamental electron heat transport process in tokamaks.

The soft $x$-ray system on ORMAK consists of nine silicon diffusedjunction diode detectors that view different fixed chords through the plasma. ${ }^{2}$ The $x$-ray signal results from plasma bremsstrahlung and recombination processese, both of which are strungly dependent on temperature and density. Thus, most of the radiation seen by a given detector comes from the small volume where the temperature and density have their largest values along the viewing chord; hence this is more of a point measurement rather than an average one. The detectors are arranged so that these points 1 ie $2 \mathrm{~cm}$ apart and àre collimated so that their spatial resolution is about $1.7 \mathrm{~cm}$. The output current of the detectors is proportional to the net radiation power in the 2 or 3 to $12 \mathrm{keV}$ energy range, where the low-energy cut-off is selected by choice of beryllium foil thickness. 
Figure 1 shows two examples of the resulting $x$-ray signal on an expanded time scale that starts at $45 \mathrm{msec}$ into the discharge, by which time steady-state conditions have been established. The principal features of the heat pulses for $r>a_{D}$ are that the times at which the pulses peak are progressively delayed, and that the pulses are broadened, as they move out from the center.

Since the soft $x$-ray detectors are only sensitive to energies above the cut-off energy $E_{c}\left(\sim 2\right.$ or $\left.3 \mathrm{keV}>\mathrm{T}_{\mathrm{e}}\right)$, in order to model the pulse propagation we develop an electron heat balance equation appropriate for the high energy electrons. Assuming that the electron distribution function retains its Maxwellian character [estimated to be valid for time scales longer than the electron-electron collision time at that energy, $\left.\tau_{e e}\left(E_{c}\right) \sim 30-50 \mu \mathrm{sec}\right]$, restricting the energy moment integration of the relevant kinetic equation to energies above $E_{c}$, and keeping only the heat conduction term, we find the appropriate electron heat balance equation to be

$$
\frac{\partial}{\partial t}\left[\frac{3}{2} n_{e} T_{e} f\right]=\frac{1}{r} \frac{\partial}{\partial r}\left[r_{e} x_{e} g \frac{\partial T}{\partial r}\right]
$$

Here,

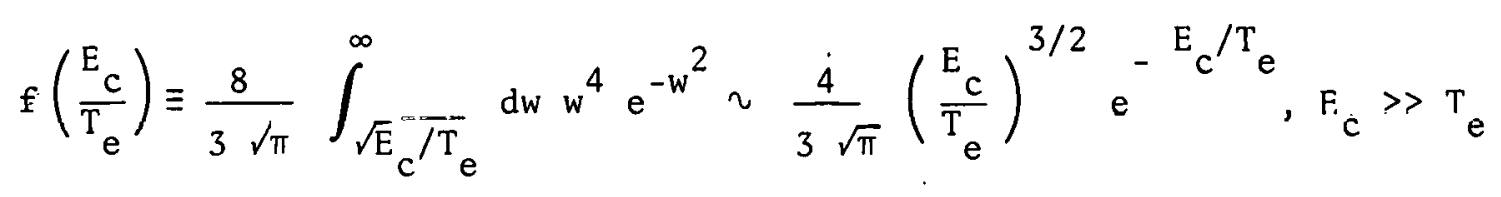

is the fraction of electron energy stored in electrons with energy greater than $E_{c} ; X_{e}\left(T_{e}\right)$ is the electron heat conduction coefficient of the Maxwellian electron component; and $g\left(E_{c} / T_{e}\right)$ is a generally unknown 
function governing the appropriate energy moment for the anomalous electron heat conduction coefficient, which is unity for $E_{c} \rightarrow 0$.

The observed temperature fluctuations are small-(typically $\Delta \mathrm{T}_{\mathrm{e}} \leq 0.2 \mathrm{~T}_{\mathrm{e}}$ ), so we solve a perturbation form of $\mathrm{Eq}$. (1). Since the internal disruptions apparently have their primary effect on the electron temperature and have little effect on the density, ${ }^{3}$ we assume $\mathrm{T}_{\mathrm{e}}$, $\mathrm{T}_{\mathrm{e}}+\Delta \mathrm{T}_{\mathrm{e}}$ with $\mathrm{n}_{\mathrm{e}}$ unchanged, and shtain for the linearized form! of Eq. (1)

$$
\frac{\partial}{\partial t}\left(\begin{array}{ll}
\frac{3}{2} n_{e} & \Delta T_{e}
\end{array}\right)=\frac{\chi_{e p}}{r} \frac{\partial}{\partial r} r \frac{\partial \Delta T_{e}}{\partial r},
$$

where

$$
x_{e p}=x_{e} g\left[f-\left(E_{c} / T_{e}\right) f^{\prime}\right]^{-1} \underline{\sim}\left(E_{c} / T_{e}\right)^{\alpha-5 / 2} x_{e}, E_{c} \gg T_{e} .
$$

Here the prime on $f$ denotes differentiacion with respect to the argument and in the last approximate equality we have assumed that for $\operatorname{large} E_{c} / T_{e}, g \cap\left(E_{c} / T_{e}\right)^{\alpha}$. For nenclassical transport, $\alpha$ is 3 ; for anomalous transport due to drift-waves and/or trapped-particle instabilities $\alpha$ is unknown, but probably lies in the range of $1.5<a<G$. Eq. (2) is a heat diffusion equation in cylindrical geometry with a diffusion coefficient that differs from that of the background distribution by a complicated and in general unknown function of $E_{c} / T_{e}$. This is because the heat pulse propagation is inferred from a high-energy group of electrons. If we had retained in Eq. (1) the energy convection, ohmic heating, radiation and other more general effects on the electron heat balance equation, the other terms would not have altered Eq. (2) since the temporal and spatial gradients of the temperature perturbation are much larger than those in the equilibrium. 
The internal-disruption effects are introduced through a heatpulse boundary condition: $\mathrm{n}_{\mathrm{e}} \mathrm{X}_{\mathrm{ep}} \partial \Delta \mathrm{T}_{\mathrm{e}} /\left.\partial \mathrm{r}\right|_{\mathrm{r}=\mathrm{a}_{\mathrm{D}}}=-\Delta \mathrm{Q} \sum_{\mathrm{n}} \delta\left(\mathrm{t}-\mathrm{n} \mathrm{t}_{\mathrm{o}}\right)$, where $\Delta Q$ is the electron energy density in each heat pulse, $t_{0}$ is the disruption repetition time, and for simplicity the heat pulses are assumed to be delta functions of time. Solving Eq. (2) by Laplace transform techriques, subject to the condition $\lim _{\mathrm{r} \rightarrow \infty} \Delta \mathrm{T}_{\mathrm{e}} \rightarrow 0$ and the above heat pulse condition, the approximate solution for the spatial region of interest $\left(a_{n} \ll r \ll a\right)$ is found to be

$$
\Delta T_{e}(r, t) \simeq \frac{a_{D} \Delta Q}{n_{e} x_{e p}} \sum_{n=0}^{N} \frac{\exp \left\{-3 r^{2} /\left[8 x_{e p}\left(t-n t_{o}\right)\right]\right\}}{t-n t_{o}}
$$

where $N=\left[t / t_{0}\right]$, the largest integer less than $t / t_{0}$. For a single isolated pulse $\left(t_{0}>3 r^{2} / 8 x_{e p}\right)$ we have

$$
\Delta T_{c} \simeq \frac{8 a_{D} \Delta Q}{3 n_{e} r^{2}}\left(\frac{t_{p}}{t}\right) e^{-t_{p} / t}, t_{p} \equiv \frac{3 r^{2}}{8 x_{e p}}
$$

The important points to note about this heat diffusion solution are: 1) the peak of $\Delta T_{e}$ occurs at $t=t_{p}$, which is proportional to $r^{2}$ and inversely proportional to $\left.x_{e p} ; 2\right)$ at a given $r, \Delta T_{e}(t)$ increases smoothly to its peak in a time $t_{p}$ and then decays roughly as $t_{p} / t$ thereafter; 3) the maxima of $\Delta \mathrm{T}_{\mathrm{e}}(\mathrm{t})$ vary inversely with $\mathrm{r}^{2}$-- a manifestation of energy conservation in the cylindrical expansion of the heat pulse.

Before making comparisons with experiment, there are additional effects we must consider. First, since $t_{p}$ is often a significant fraction of the pulse repetition time $t_{0}$, we consider $t \gg t_{0}$ and take 
account of the summation in Eq. (4). Second, what is measured is the change in the soft $x$-ray intensity $(\Delta I)$ and not simply $\Delta T_{e}$. However, as 1ong as $\Delta \mathrm{T}_{\mathrm{e}} \ll \mathrm{T}_{\mathrm{e}}^{2} / \mathrm{E}_{\mathrm{c}}, \Delta \mathrm{I}$ is proportional to $\Delta \mathrm{T}_{\mathrm{e}}$. Finally, we take account of the fact that the signals from the detector array are put through a $100 \mathrm{~Hz}$ high-pass filter before display, by multiplying the Laplace transform of $\Delta T_{e}$ by the transform of the filter function and using the convolution theorem to perform the inverse transform.

The experimental data are compared with the diffusive model in Fig. 2. The first point, demonstrated in Figures $2 a$ and $2 b$, is that $t_{p}$ agrees with the predicted asymptotic $r^{2}$ dependence. Second, the pulse shapes follow calculated curves that include the effects of observed repetition rates and filtering (see Fig. 2c). Finally, Fig. $2 \mathrm{~d}$ shows that the maximum $\Delta \mathrm{T}_{\mathrm{e}}$ decreases roughly as $1 / \mathrm{r}^{2}$. Thus, within the limits of statistical scatter inherent in these measurements, the data show reasonable agreement with the heat conduction model. It should be noted that due to the general irreproducibility of discharges with highly visible sawteeth, ${ }^{2}$ approximate profiles must be used when. converting the signal, $\Delta \mathrm{I}$, to temperature values, $\Delta \mathrm{T}_{\mathrm{e}}$, for measurements such as the energy conservation of Fig. 2d.

Alternative models for the pulse behavior have been considered, but no satisfactory ones found. Wave propagation cannot account for the smooth leading edge of the pulse, and would require max $\left(\Delta \mathrm{T}_{e}\right)$ to decrease as $r^{-1 / 2}$, instead of the observed sharper fall-off. The data also do not fit with a ballistic or macroscopic plasma flow model since in 
these cases the temperature pulses should simply propagate out through the plasma, essentially unchanged.'

Thus, we conclude that the heat pulses produced by internal disruptions propagate out through the middle (confinement)region of ORMAK by a diffusive process, at least on length scales longer than about one centimeter. Providing $X_{e}$ can be kept small enough, this bodes well for the future of tokamaks, which rely on this diffusive property for their favorable size scaling.

Next, we compare the rate of this process with the gross electron energy transport. Since $t_{p}$ is found to be roughly dependent on $r^{2}$ (Figs. 2a,b), the inferred heat conduction coefficient $x_{\text {ep }}$ appears to be reasonably constant over the region observed. For comparison purposes, if we assume that electron heat conduction with coefficient $x_{e}\left(T_{e}\right)$ is the dominant heat loss term in ORMAK and that the disruptive and edge layers are thin $\left(a_{D},\left|a-a_{0}\right| \ll a\right)$ then

$$
\tau_{E e} \simeq a^{2} / 4 x_{e}
$$

where $\tau_{E e}$ is the electron energy containment time obtained by the usual method of dividing the stored energy by the power input (ohmic, plus the fraction of injection power to the electrons, minus the power transferred to the ions). The $x_{\text {ep }}$ determined from heat-pulse propagation is compared with the $x_{e}$ determined from Eq. (6) in Fig. 3a. The comparison shows that: 1) there is little correlation between $x_{e p}$ and $x_{e}$; 2) $x_{e p}$ exceeds $x_{e}$ by factors ranging from 2.5 to 15 ; and 3 ) both $x_{e}$ and $x_{e p}$ substantially exceed the neoclassical values of $(1-10) \times 10^{2} \mathrm{~cm}^{2} / \mathrm{sec}$ for these discharges. 
In order to discover experimentally the relation of $x_{e p}$ to $x_{e}$, which according to Eq. (3) should be solely a function of $E_{c} / T_{e}$, we would like to consider data having the same $X_{e}$. Somewhat fortuitously, most of the available data have nearly the same $x_{e}\left(\sim 2 \times 10^{4} \mathrm{~cm}^{2} / \mathrm{sec--}\right.$ see Fig. 3a). By selecting these data and plotting the respective $X_{\text {ep }}$ 's versus $\mathrm{E}_{\mathrm{c}} / \mathrm{T}_{\mathrm{e}}+1$ (a normalized measure of the electron energy group dominating the signals), we obtain the plot shown in fig. 3b. It shows that: 1) $\chi_{e p}$ increases with $\mathrm{E}_{c} / \mathrm{T}_{e}$; and 2) the relation for discharges with neutral injection is both more systematic than and different from that with no injection. Here, $\mathrm{T}_{\mathrm{e}}$ at $\mathrm{r} / \mathrm{a} \approx 0.5$ has been taken to be half the central value because of the lack of sufficient profile information. The definitive test of changing $\mathrm{E}_{c}$ for sequential discharges has not yet been performed. Nonetheless, the degree of correlation apparent in Fig. 3b, particularly for the cases with neutral injection, and the fact that the $x_{e}$ obtained from extrapolation of the data to $E_{c} \rightarrow 0$ is reasonably consistent with the gross $X_{\mathrm{e}} \approx 2 \times 10^{4} \mathrm{~cm}^{2} / \mathrm{sec}$, leads us to conclude that the difference between $X_{e p}$ and $X_{e}$ is due to the fact that $x_{e p}$ is obtained from electrons with $E_{2} \geq E_{c} \gg T_{c}$. By more extensive measurements of the functional dependence of $X_{e p}$ on $E_{c} / T_{e}$ such as those in Fig. 3b, one could apparently determine the energy dependence of the kernel of the anomalous electron heat conduction coefficient and thereby gain an important insight into the anomalous transport process in tokamaks.

The authors are particularly grateful to J. L. Dunlap and J. H. Harris for their close experimental participation, to the TFR group (Fontenay-aux-Roses, France) for constructive communications on related work, and to J. L. Whitson for the numerical computations. They are 
also grateful to R. A. Dandl, who first suggested the high energy group hypothesis for the difference between $X_{e p}$ and $X_{e}$, and to $R$. G. Bateman, L. A. Berry, J. F. Clarke, H. C. Howe, M. Murakami, O. P. Manley, J.:A. Rome and K. T. Tsang for many useful discussions of this work.

\section{REFERENCES}

1. S. von Goeler, W. Stodiek and N. Sauthoff, Phys. Rev. Lett. 33, 1201 (1974).

2. J. L. Dunlap, G. L. Jahns and J. H. Harris, Bull. Am. Phys, Soc. II 20, 1255 (1975); J. L. Dunlap et al., to be published.

3. J. Tachon, TFR Group paper presented at the annual meeting on Theoretical Aspects of Controlled Thermonuclear Research, Washington, D. C., April 7-9, 1975; private communication.

4. F. L. Hinton and M. N. Rosenbluth, Phys. Fluids 16, 836 (1973) and references cited therein. 
FIGURE CAPTIONS .

Fig. 1. Composite oscillograms of soft $x$-ray signals for two discharges. For both cases, the top trace gives the signal from one detector over the full time of the discharge; the rest of the signals are on an expanded timescale starting at 45 msec, which falls in the middle of the full-time trace. The temporal variation in the signal (sharp fall inside, sharp rise outside) shows that $a_{D}$ is $\simeq 5 \mathrm{~cm}$ for shot 11389 and $\sim 8 \mathrm{~cm}$ for shot 13477 . The signals labeled $\dot{\mathrm{B}}_{0}$ are poloidal magnetic field fluctuations from pickup loops.

Fig. 2. Comparison of data with the diffusive mode1: (a) Peak arrival time versus radial position. The slope of the asymptote is $3 /\left(\begin{array}{ll}8 & X_{e p}\end{array}\right)$ and thus gives a measurement of $x_{e p}$ (b) $t_{p}$ versus $\mathrm{r}^{2}$ in normalized units for a representative set of discharges. Each symbol corresponds to one discharge, for which $x_{e p}$ has been obtained from a plot such as Fig. 2a. Solid symbols are discharges with neutral beam injection, and open symbols are for no injection. (c) Graphical reconstruction of one set of pulses (third from left in Fig. 1, shot 11389) compared with normalized computer-gencräed pulsc shapcs. (d) Maxlmum $\Delta \mathrm{T}_{\mathrm{e}}$ (normalized) inferred from $x$-ray signal level as a function of radius.

Fig. 3. (a) Comparison of $X_{e p}$ with $\chi_{e}$ obtained from $\tau_{F e}$ via Eq. (6).

(b) Dependence of $x_{e p}$ on the electron energy parameter $\mathrm{E}_{\mathrm{c}} / \mathrm{T}_{\mathrm{e}}+1$ for discharges with $1.8 \leq \mathrm{X}_{\mathrm{e}} \leq 2.9 \times 10^{4} \mathrm{~cm}^{2} / \mathrm{sec}$. 
SHOT 11389

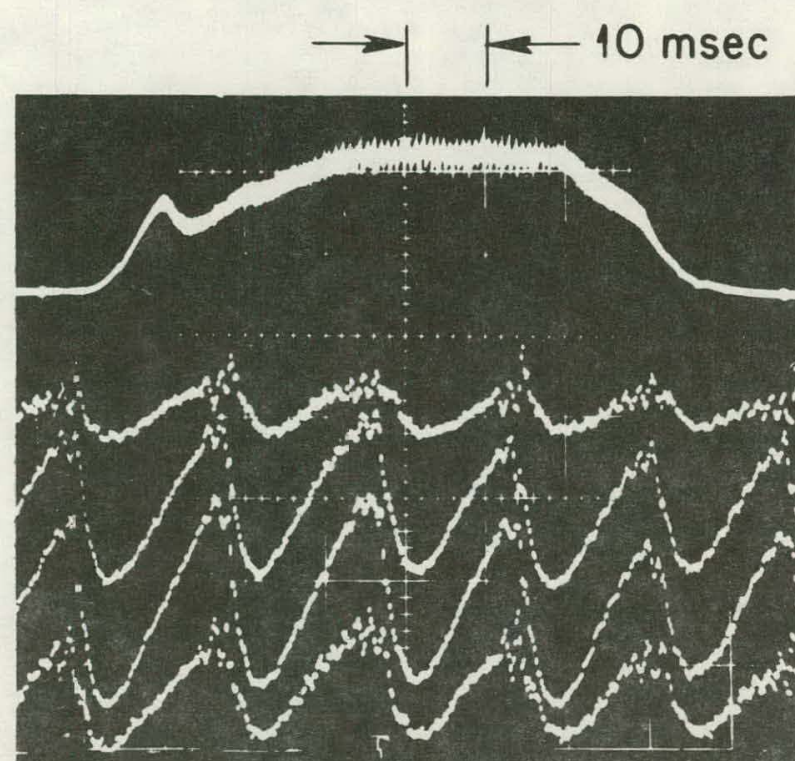

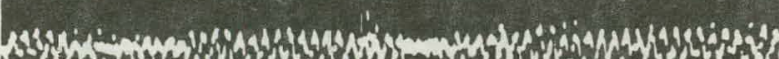

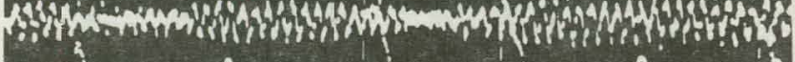

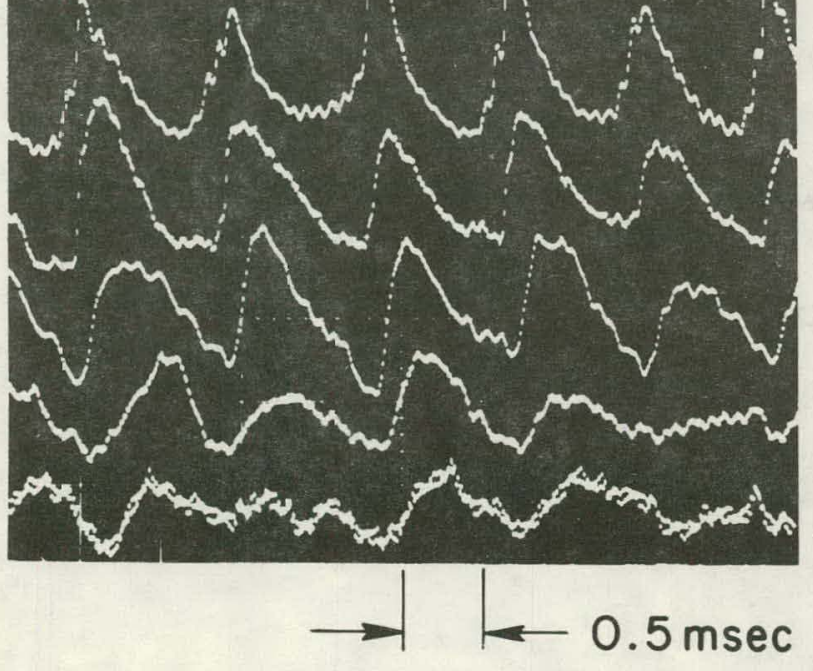

SHOT 13477

ORNL- DWG $76-4247$

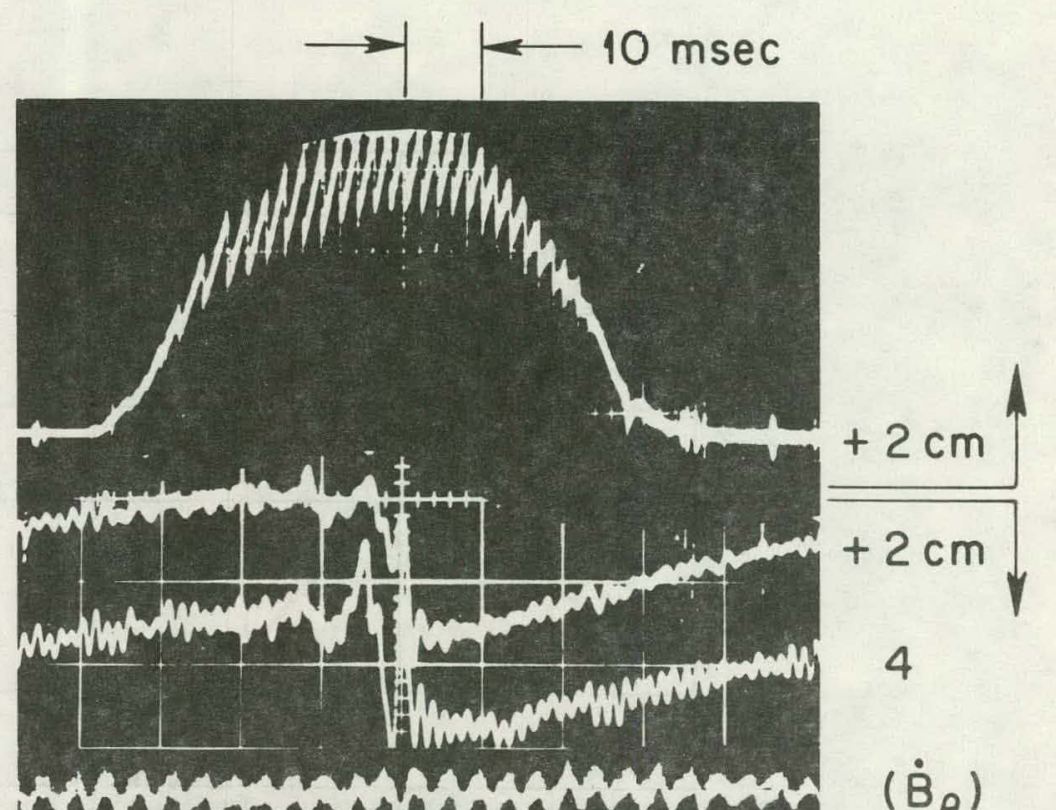

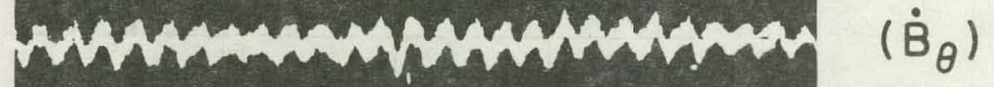

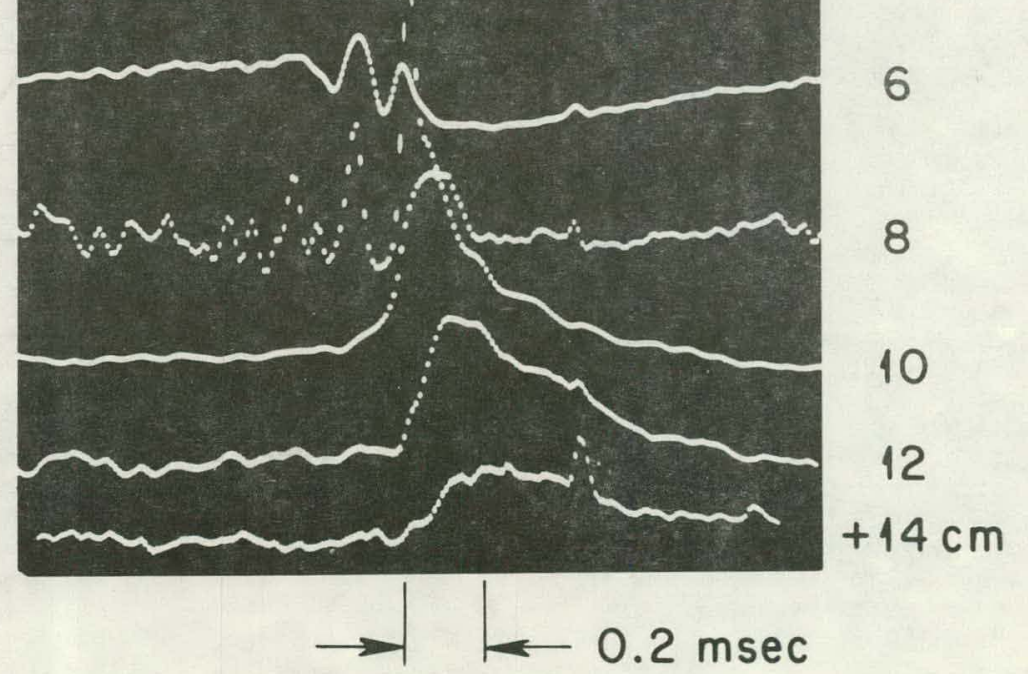

Fig. 1 


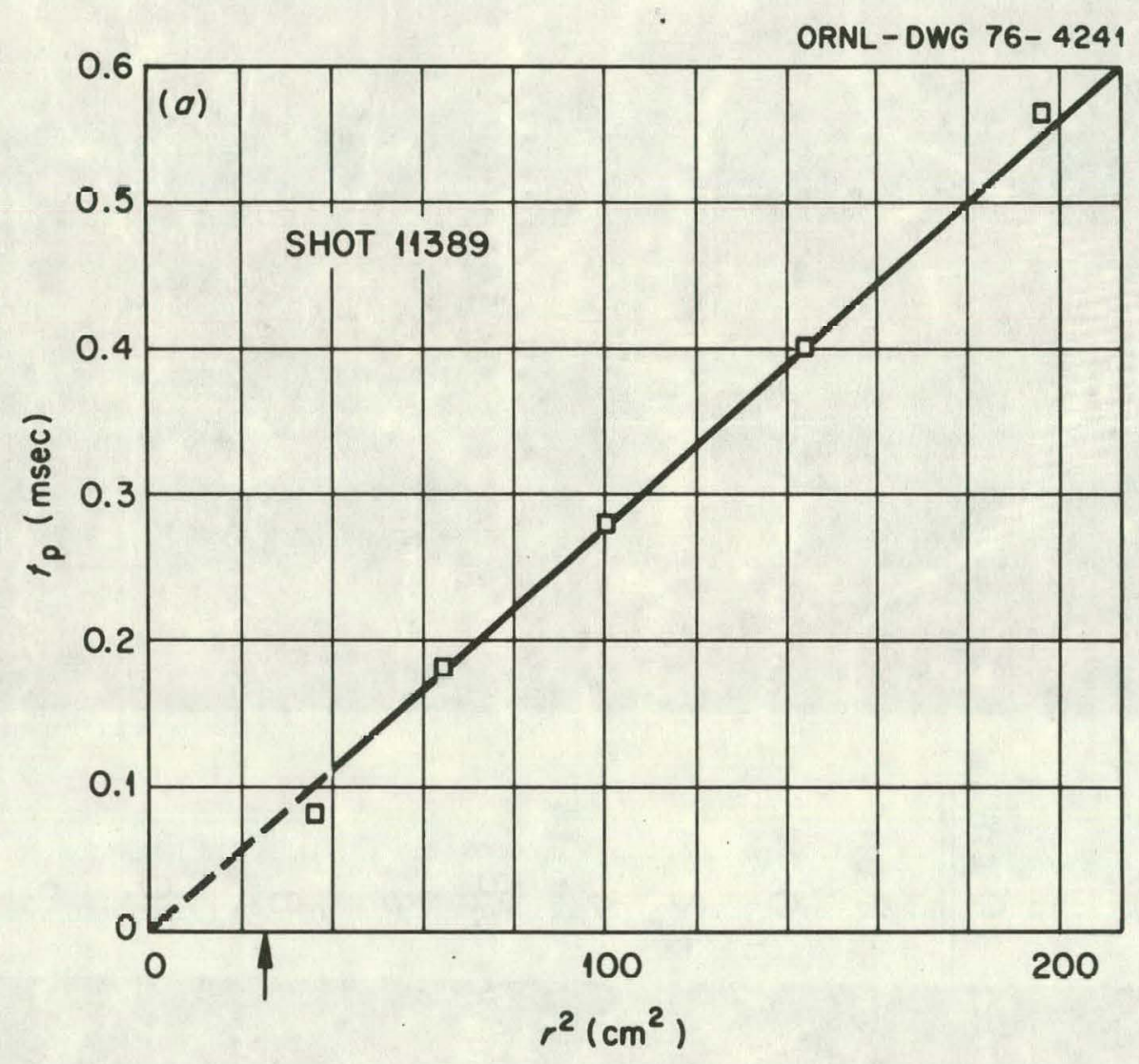

Fig. 2a 


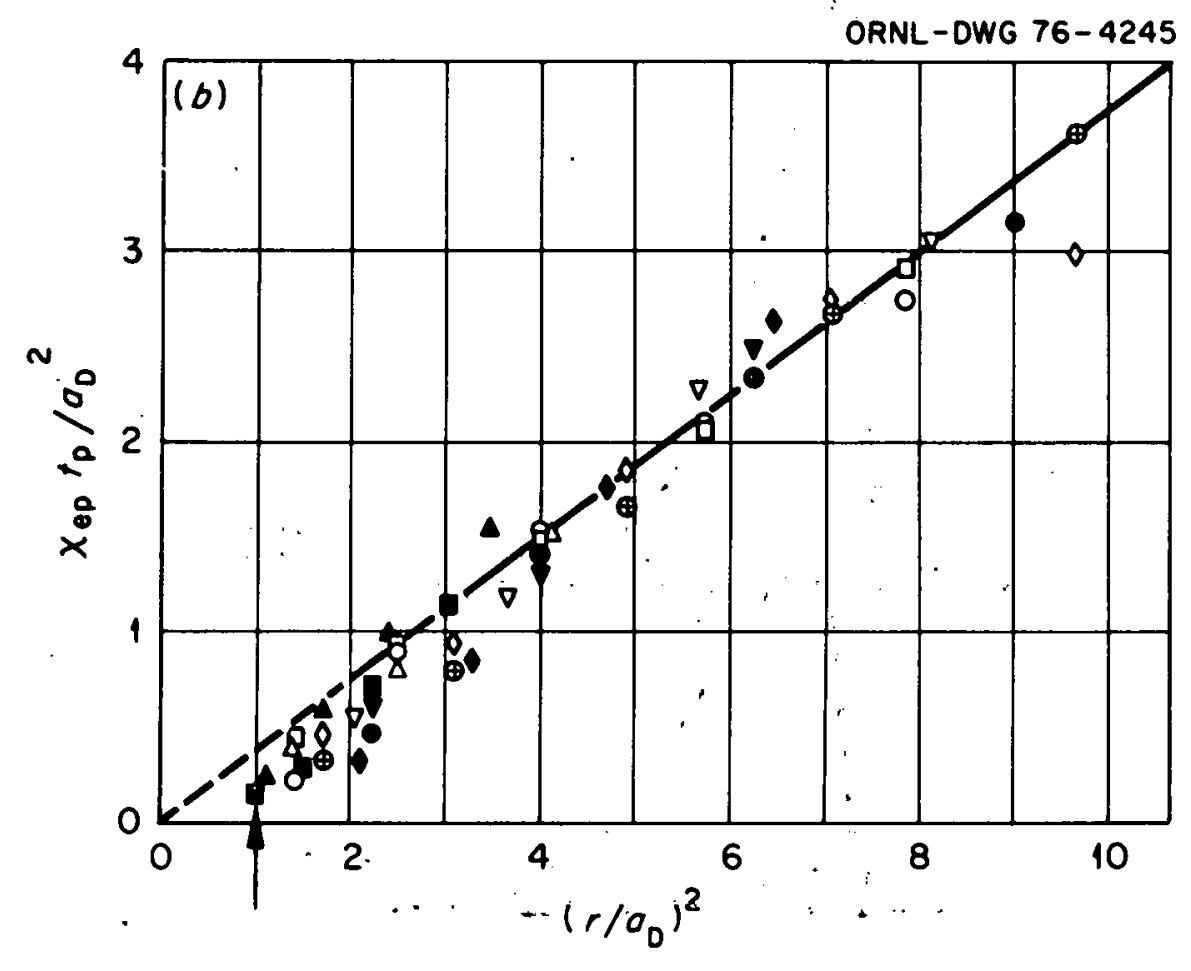

Fig: $2 b$. 


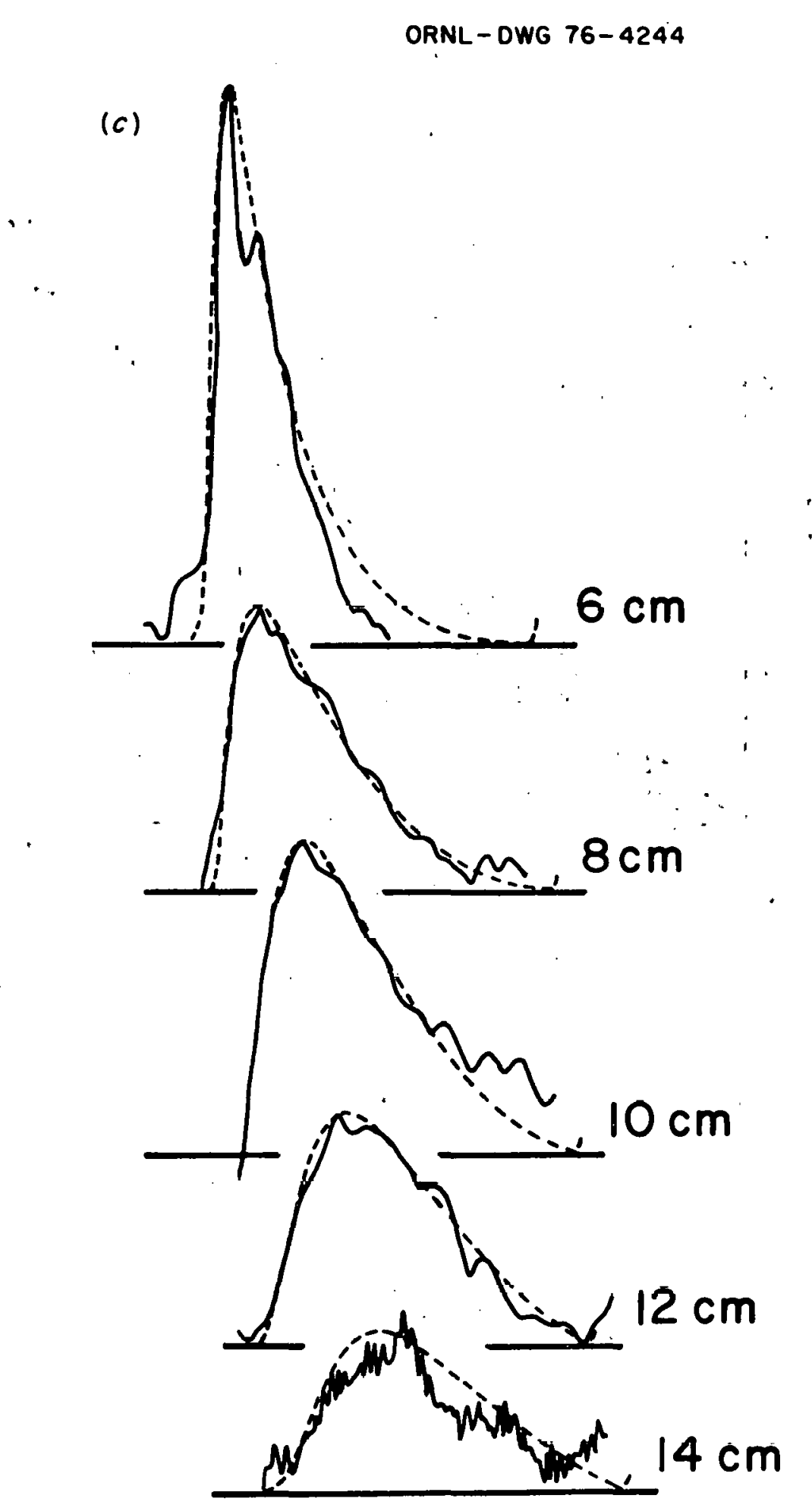

Fig. 2c 


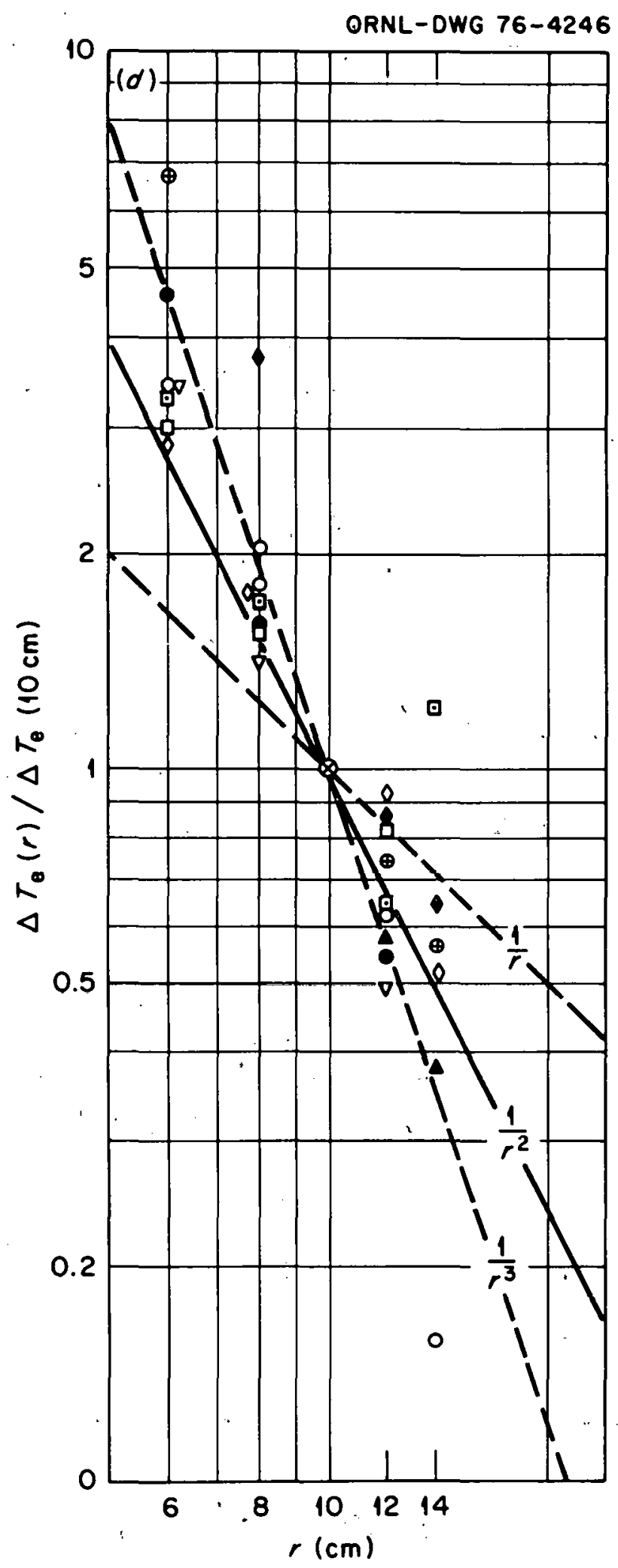

Fig. 2d 


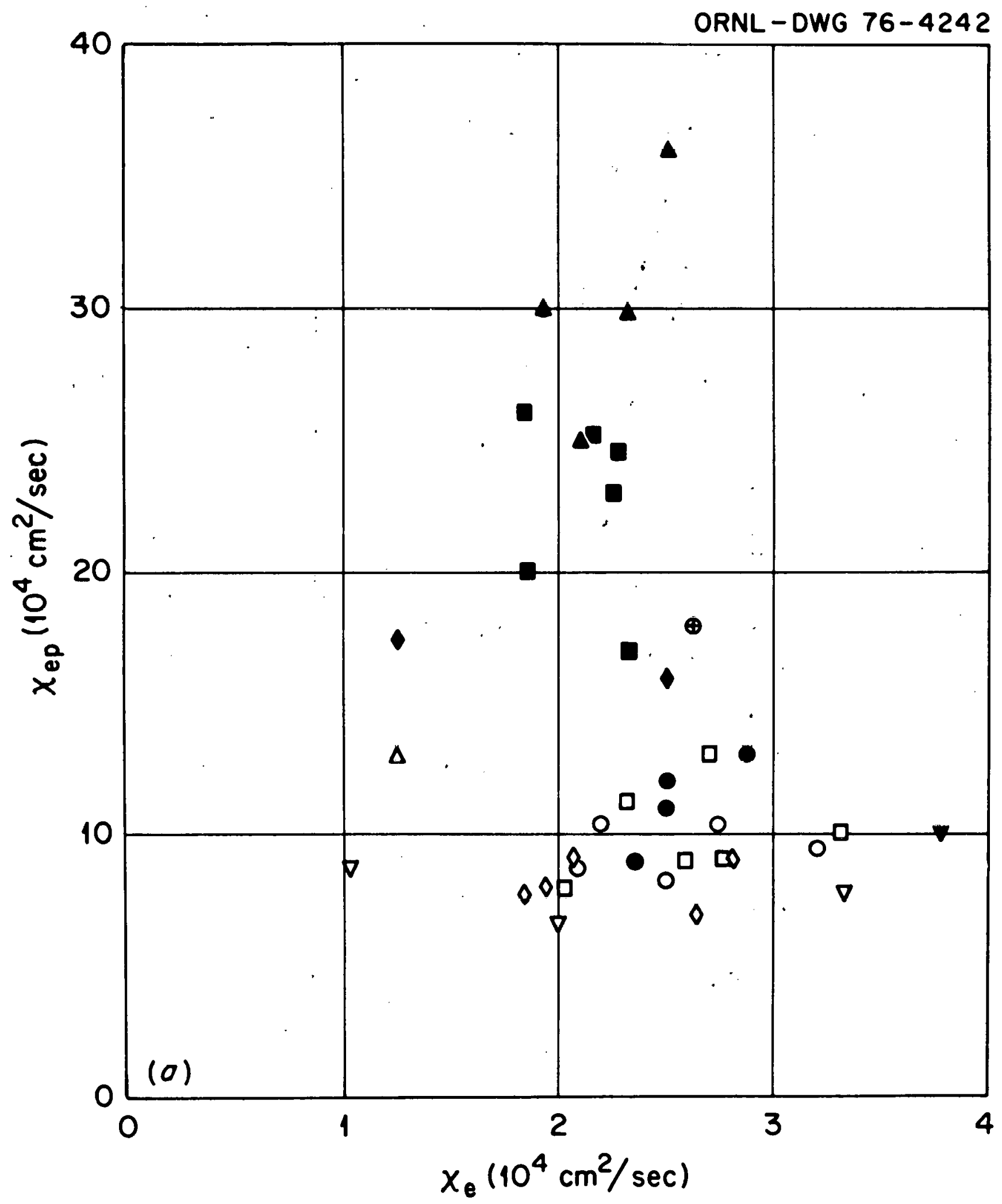

Fig. 3a 


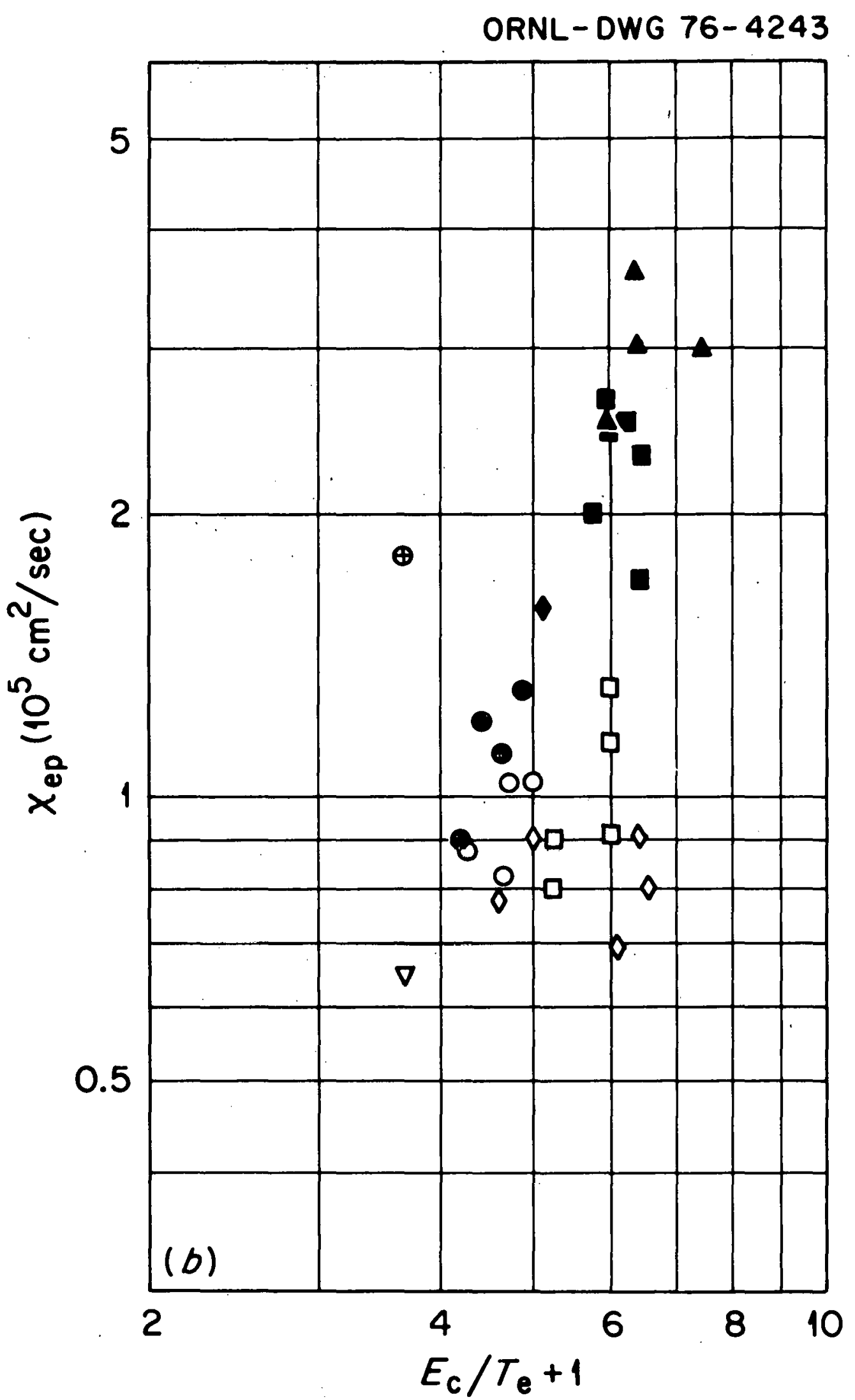

Fig. 3b 
THIS PAGE

WAS INTENTIONALLY

LEFT BLANK 


\section{INTERNAL DISTRIBUTION}

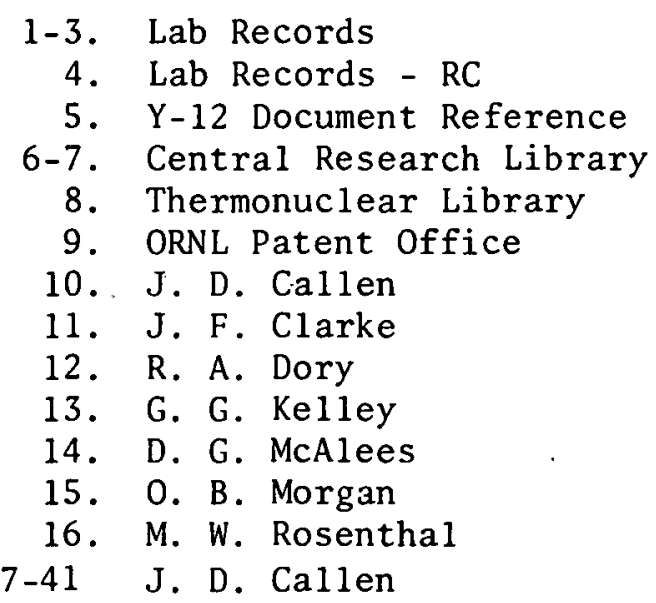

EXTERNAL DISTRIBUTION

42. Plasma Physics Library, Plasma Physics Laboratory, Princeton Univ., Forrestal Campus, P.O. Box 451, Princeton, NJ 08540

43. Controlled Thermonuclear Research Library, Lawrence Livermore Laboratory, P.0. Box 808, Livermore, CA 94550

44. Q Division Library, $c / 0 \dot{F}$. L. Ribe, Lós Alamos Scientific Laboratory, P.0. Box 1663, Los Alamos; NM 87544

45. Controlled Thermonuclear Research Library, c/o Weston M. Stacey, Jr., Argonne National Laboratory; 9700 S. Cass Ave., Argonne, IL 60439

46. CTR Computer Center, c/o Dr. John Killeen, Lawrence Livermore Laboratory, P.0. Box 808, Livermore, CA 94550

47. Librarian, Culham Laboratory, U.K. Atomic Energy Authority, Abingdon, Oxon, OX14, 3DB, United Kingdom

48. Ruth Lengye, Bibliothek, Max Planck Institut für Plasmaphysik, 8046 Garching bei München, Federal Republic of Germany

49. Library, Centre de Récherches en Physique des Plasma, 21 Avenue des Bains, 1007, Lausanne, Switzerland

50. A. M. Dupas, Documentation S.I.G.N., Department de La Physique du Plasma, Et de La Fusion Controlée, Association EURATOM-CEA, Sur La Fusion, Centre d'Etudes Nucleaires, BP 85 Centre Du TRI 38041 Grenoble Cedex (France)

51. Bibliothéque, Service du Confinement des Plasmas, C.E.A., B.P. No. 6, 92, Fontenay-aux-Roses (Seine) France 
52. Library, International Centre for Theoretical Physics, Trieste, Italy

53. Library, Laboratorio Gas Ionizati, Frascatti, Italy

54. V. E. Ivanov, Physical-Technical Institute of the Ukranian Academy of Sciences, Sukhumi, U.S.S.R.

55. M. S. Rabinovich, Lebedev Institute of Physics, Academy of Sciences of the U.S.S.R., Leninsky Prospect 53, Moscow, U.S.S.R.

56. Thermonuclear Laboratory, Kurchatov Institute of Atomic Energy, 46 IIIit.sa Kilrchatova, P.U. Box 3402. Moscow. U.S.S.R.

57. Library, Institute for Plasma Physics, Nagoya University, Nagoya, Japan 464

58. Library, FOM-Institut voor Plasma-Fysica, Rijnhuizen, Jutphaas, Netherlands

59. Plasma Physics Group, Department of Engineering Physics, Australian National University, P.0. Box 4, Canberra A.C.T. 2600 Australia

60. Thermonuclear Library, Japan Atomic Energy Research Institute, Tokai, Naka, Ibaraki, Japan

61. CTR Reading Room, c/o Prof. Dieter J. Sigmar, Room 37-391, MIT, Cambridge, MA 02139

62. CTR Reading Room, c/o Prof. D. W. Kerst, Dept. of Physics, Sterling Ha11, Univ. of Wisconsin, Madison, WI 53706

63. CTR Reading Room, c/o Prof. I. B. Bernstein, Yale Univ., New Ilaven, CT 06510

64. Center for Plasma Physics and Thermonuclear Research, c/o D. W. Ross Univ. of Texas, Physics Dept., Austin, TX 78712

65. CTR Reading Room, c/o Prof. B. D. Fried, Physics Dept., Univ. of California, Los Angeles, CA 90024

66. CTR Reading Room, c/o Prof. David C. Montgomery, Physics \& Astronomy Dept., Univ. of Iowa, Iowa City, IA. 52240

67. Magneto-Fluid-Dynamics Library, Courant Inst. of Math. Sci., New York Univ., 251 Mercer St., New York, NY 10012

68. CTR Reading Room, c/o Prof. Allan N. Kaufman, Physics Dept., Univ. of California, Berkeley, CA. 947.20

69. CTR Reading Room, c/o Prof. W. B. Thompson, Physics Dept., Univ. of California, San Diego, La Jollà, CA 92037 
70. CTR Reading Room, c/o Prof. Alvin W. Trivelpiece, Dept. of Physics \& Astronomy, Univ. of Maryland, College Park, MD 20742

71. CTR Reading Room, c/o Prof. T. Kammash, 103 Research Admin. B1dg., N. Campus, Univ. of Michigan, Ann Arbor, MI 48105

72. CTR Reading Room, c/o Dr. Ravi N. Sudan, Phillips Hall, Cornell Univ., Ithaca, NY 18450

73. Prof. Marshall N. Rosenbluth, Institute for Advanced Study, Princeton, NJ 08540

74. CTR Reading Room, c/o Prof. R. Gross, Plasma Research Lab., Columbia Univ., New York, NY 10027

75. CTR Reading Room, c/o Prof. Roy Gould, California Inst. of Tech., Pasadena, CA 91103

76. Dr. Nicholas A. Kral1, Science Applications, Inc., P.0. Box 2354, 1200 Prospect St., La Jolla, CA 92037

77. CTR Reading Room, c/o Dr. Jay P. Boris, Plasma Physics, Naval Research Laboratory, Washington, DC 20390

78. CTR Library, General Atomic Co., P.0. Box 81608, San Diego, CA 92138

79. CTR Library, $c / 0$ Dr. Alan F. Hanght, United Technologies Research Labs, East Hartford, CT 06108

80. Dr. Robert E. Price, Division of Controlled Thermonuclear Research, Energy Research and Development Administration, Washington, DC 20545

81. Dr. Bennett Miller, Division of Controlled Thermonuclear Research, Energy Research and Development Administration, Washington, DC 20545

82. Dr. Arthur Sleeper, Division of Controlled Thermonuclear Research, Energy Research and Development Administration, Washington, DC 20545

83. Dr. Walter Sadowski, Division of Controlled Thermonuclear Research, Energy Research and Development Administration, Washingtion, DC 20545

84. Dr. D. H. Priester, Division of Controlled Thermonuclear Research, Energy Research and Development Administration, Washington, DC 20545

85. Dr. E. E. Kintner, Division of Controlled Thermonuclear Research, Energy Research and Development Administration, Washington, DC 20545 
86. Dr. L. D. Pearlstein, L-388, Lawrence Livermore Laboratory, P.0. Box 808, Livermore, CA 94550

87. Dr. J. P. Friedberg, Los Alamos Scientific Laboratory, Los Alamos NM 87544

88. Dr. David J. Rose, Dept. of Nuclear Engineering, MIT, Cambridge, MA 02139

89. Dr. Gareth E. Guest, General Atomic Co., P.0. Box 81608, San Diego, CA 92138

90. Dr. Claude Mercier, Service du Theorie des Plasmas, Centrc d'Etudes Nucleaires, Fontenay-aux-Koses (Seine) France

91. Dr. J. B. Taylor, Culham Laboratory, UKAEA Abingdon, Oxon, OX14 $\overline{\mathrm{S}} \overline{\mathrm{D}} \overline{\mathrm{B}}$, United Kingdom

92. Dr. D. Pfirsch, Institute for Plasma Physics, 8046 Garching bei München, Federal Republic of Germany

93. Dr. V. D. Shafranov, I. V. Kurchatov Inst. of Atomic Energy, 46 Ulitsa Kurchatova, P.0. Box 3402 , Moscow, U.S.S.R.

94. Dr. Harold Grad, Courant Inst. of Math. Sci., New York Univ., 251 Mercer St., New York, NY 10012

95. Dr. J. G. Cordey, Culham Laboratory, UKAEA, Abingdon, Oxon, OX14, 3DB, United Kingdom

96. Dr. David Baldwin, L-388, Lawrence Livermore Lab., P.0. Box 808, Livermore, CA 94550

97. Prof. Bruno Coppi, Dept. of Physics, MIT, Cambridge, MA 02139

98. Dr. Harold P. Furth, Princeton Plasma Physics Lab., Princeton Univ., P.0. Box 451, Princeton, NJ 08540

99. Dr. Paul Il. Rutherford, Princeton Plasma Physics Lab., Princeton Univ., Princeton, NJ 08510

100. Dr. Herbert H. Woodson, Dept. of Electrical Engineering, Univ. of Texas, Austin, TX 78712

101. Research \& Technical Support Div., ORO, ERDA

102-128. Tech. Information Center, ERDA, OR 